\title{
Combining intratumoral Treg depletion with androgen deprivation therapy (ADT): preclinical activity in the Myc-CaP model
}

\author{
Ying-Chun Shen ${ }^{1,2,3} \cdot$ Ali Ghasemzadeh ${ }^{1,4,5,6} \cdot$ Christina M. Kochel ${ }^{1,10} \cdot$ Thomas R. Nirschl2,4 $^{2, \text { Brian J. Francica }}{ }^{1,11}$. \\ Zoila A. Lopez-Bujanda ${ }^{1,4,6,7} \cdot$ Maria A. Carrera Haro ${ }^{1,4,6} \cdot$ Ada Tam $^{1,4} \cdot$ Robert A. Anders $^{7} \cdot$ Mark J. Selby ${ }^{8}$. \\ Alan J. Korman ${ }^{8} \cdot$ Charles G. Drake $^{1,6,9,12}$
}

Received: 3 August 2017 / Accepted: 29 September 2017 / Published online: 4 December 2017

(C) The Author(s) 2018. This article is published with open access

\begin{abstract}
Background Immune checkpoint blockade has shown promising antitumor activity against a variety of tumor types. However, responses in castration-resistant prostate cancer remain relatively rare-potentially due to low baseline levels of infiltration. Using an immunocompetent cMyc-driven model (Myc-CaP), we sought to understand the immune infiltrate induced by androgen deprivation therapy (ADT) and to leverage that infiltration toward therapeutic benefit.

Methods Using flow cytometry, qPCR and IHC, we quantified ADT-induced immune infiltration in terms of cell type and function. Preclinical treatment studies tested the combinatorial effects of ADT and immune checkpoint blockade using tumor outgrowth and overall survival as end points.

Results ADT induces a complex pro-inflammatory infiltrate. This pro-inflammatory infiltrate was apparent in the early postcastration period but diminished as castration resistance emerged. Combining ADT with tumor-infiltrating regulatory $\mathrm{T}$ cell (Treg) depletion using a depleting anti-CTLA-4 antibody significantly delayed the development of castration resistance and prolonged survival of a fraction of tumor-bearing mice. Immunotherapy as a monotherapy failed to provide a survival benefit and was ineffective if not administered in the peri-castration period.

Conclusions The immune infiltrate induced by ADT is diverse and varies over time. Therapeutic strategies focusing on depleting Tregs in the peri-castration period are of particular interest.
\end{abstract}

\section{Introduction}

Immune checkpoint blockade, which amplifies host immunity to eradicate cancer cells, has emerged as a paradigm-shifting

Electronic supplementary material The online version of this article (https://doi.org/10.1038/s41391-017-0013-x) contains supplementary material, which is available to authorized users.

$\triangle$ Charles G. Drake

cgd2139@columbia.edu

1 Department of Oncology, Sidney Kimmel Comprehensive Cancer Center, Johns Hopkins University School of Medicine,

Baltimore, MD, USA

2 Department of Oncology, National Taiwan University Hospital, Taipei, Taiwan

3 Graduate Institute of Oncology, School of Medicine, National Taiwan University, Taipei, Taiwan

4 Bloomberg-Kimmel Institute for Cancer Immunotherapy, Johns Hopkins University School of Medicine, Baltimore, MD, USA

5 Medical Scientist Training Program, Johns Hopkins University School of Medicine, Baltimore, MD, USA cancer treatment [1]. Blockade of cytotoxic $\mathrm{T}$ lymphocyte antigen-4 (CTLA-4), programmed cell death-1 (PD-1), or programmed cell death ligand-1 (PD-L1) results in durable tumor regression in a proportion of patients with a variety of treatment refractory cancers as well as in some patients with treatment-naive tumors [2]. Prostate cancer has proved more challenging than other tumor types; despite promising early

6 Columbia Center for Translational Immunology, Columbia University Medical Center, New York, NY, USA

7 Department of Pathology, Johns Hopkins University School of Medicine, Baltimore, MD, USA

8 Bristol-Myers Squibb, Redwood City, CA, USA

9 The Brady Urological Institute, Johns Hopkins University, Baltimore, MD, USA

10 Tizona Therapeutics, South San Francisco, CA, USA

11 Aduro Biotech, Berkeley, CA, USA

12 Present address: Herbert Irving Comprehensive Cancer Center, Columbia University Medical Center, New York, NY, USA 
results [3], CTLA-4 blockade failed to show efficacy in two randomized Phase III trials $[4,5]$. Further, the first Phase Ib trial of an anti-PD-1 antibody included 17 late-stage prostate cancer patients with no objective responses noted [6]. More recently, objective responses have been reported when anti-PD-1 was added to patients progressing on the second-generation antiandrogen enzalutamide [7], suggesting that a subset of prostate cancer patients may indeed respond to PD-1 blockade.

Androgen deprivation therapy (ADT) is the standard firstline treatment for recurrent or metastatic prostate cancer $[8,9]$. In addition to its pro-apoptotic effects on cancer cells [10], ADT results in immune infiltration into the prostate gland [11, 12]. This infiltrate is complex and includes potential antitumor effector cells such as CD8 T cells as well as CD68+ macrophages [12]. Conversely, infiltrating B cells may serve to promote castration resistance [13]. Previously, we found that castration results in the de novo presentation of a prostaterestricted antigen in the tumor-draining lymph nodes and that the initial pro-inflammatory effects of ADT were sufficient to transiently mitigate T-cell tolerance [14].

Regulatory $\mathrm{T}$ cells (Tregs) are an especially interesting feature of intraprostatic inflammation [15]. We have found that transient depletion of tumor-infiltrating Tregs by lowdose cyclophosphamide augmented an antitumor vaccine response against prostate cancer in mice [16]. In patients, a high level of tumor-infiltrating Tregs has been associated with shorter disease-free survival in patients who underwent radical prostatectomy [17]. Taken together, these data suggest that the pro-inflammatory effects of ADT may be counterbalanced by pro-tumorigenic Tregs.

Preclinical studies on the effects of Treg on antitumor immunity induced by ADT have been hampered by the lack of an effective Treg-depleting reagent. To address that issue, we used an anti-CTLA-4 antibody of the mouse IgG2a isotype, which selectively depletes intratumoral Tregs based on their relatively elevated expression of CTLA-4 [18]. For an animal model, we used the castration-sensitive Myc-CaP model developed by the Sawyers group; these tumor cells initially respond to ADT but subsequently develop androgen independence, modeling castration-resistant prostate cancer progression in humans [19]. We found that Treg depletion in the peri-castration period significantly altered the immunological composition of prostate tumor microenvironment (TME) and resulted in prolonged survival in a subset of animals. Treg depletion without ADT was ineffective, as was Treg depletion in more advanced settings.

\section{Materials and Methods}

\section{Mice}

Six-to-8-week-old male FVB/NJ mice were purchased from The Jackson Laboratory (Bar Harbor, ME) and housed in a specific pathogen-free facility at the Johns Hopkins University School of Medicine. Sample group sizes were selected based on extensive experience with these models. After tumors were established, animals were randomly assigned to treatment groups in all experiments. Investigators were not blinded to the groups during the experiments. All animal experiments were performed in accordance with a protocol approved by the Institutional Animal Care and Use Committee at the Johns Hopkins University School of Medicine.

\section{Cell line}

Myc-CaP cells, derived from spontaneous prostate cancer in c-Myc transgenic mice, were a generous gift from Dr. Charles Sawyers and were maintained as previously described [19]. Cells were tested to be free of mycoplasma contamination.

\section{Animal model}

Eight-to-10-week-old male FVB/NJ mice were subcutaneously inoculated with Myc-Cap cells $\left(1 \times 10^{6}\right.$ cells/ mouse) in the right flank as previously described [13]. Tumor diameters were measured with an electronic caliper every $2-3$ days as indicated. Tumor volumes were calculated using the formula: $0.5 \times$ longest diameter $\times(\text { shortest diameter })^{2}$. When tumor volumes reached approximately $400 \mathrm{~mm}^{3}$, mice were randomly allocated to treatment groups as indicated. Euthanasia was performed for tumor ulceration, tumor diameter $>2 \mathrm{~cm}$, or tumor volume $>1500 \mathrm{~mm}^{3}$. Overall survival (OS) was defined as the time period between castration and death.

\section{Androgen deprivation therapy}

ADT was delivered via bilateral orchiectomy or subcutaneous (sc) injection of degarelix acetate (a GnRH receptor antagonist; Ferring Pharmaceuticals Inc., Parsippany, NJ) at a dosage of $0.625 \mathrm{mg}$ in $100 \mu \mathrm{l}$ vehicle every 30 days.

\section{Immune checkpoint blockade}

Anti-PD-1 (murine IgG1, clone 4H2) [20], anti-CTLA-4 non-depleting (ND; murine IgG1-D265A; a non-FcyRbinding mutant with deficient FcyR-mediated depletion), and anti-CTLA-4 depleting (D; murine IgG2a; with competent Fc $\gamma$ R-mediated depletion) [21] were used. Antibody treatment was administered via intraperitoneal (ip) injection at a dose of $10 \mathrm{mg} / \mathrm{kg}$ body weight every 3 days for a total of 3 doses. Mouse IgG2a (clone: C1.18.4; BioXCell, West Lebanon, $\mathrm{NH}$ ) was used as an isotype control. 


\section{Quantification of serum testosterone}

Whole blood was collected from the tail vein and allowed to clot for $1 \mathrm{~h}$ at $4{ }^{\circ} \mathrm{C}$. Serum was obtained by centrifuging $(1000 \times g$ for $30 \mathrm{~min})$ and collecting the supernatant. Sera were stored at $-80^{\circ} \mathrm{C}$ prior to analysis. Testosterone concentration was determined by enzyme-linked immunosorbent assay according to the manufacturer's instructions (Enzo, Farmingdale, NY).

\section{Quantitative reverse transcriptase-PCR}

Subcutaneous Myc-CaP tumors were harvested and digested with collagenase I and trypsin (Gibco, Carlsbad, CA). Total RNA was extracted using Trizol (Ambion, Carlsbad, CA). cDNA was prepared from total RNA using the RNA to cDNA EcoDry Premix (Clontech, Mountain View, CA). Real-time assays were conducted using TaqMan real-time probes (Applied Biosystems, Foster City, CA). All samples were run in triplicate. The $\Delta \Delta \mathrm{CT}$ method was used to quantify relative mRNA expression. Expression of each target gene was normalized to that of a reference gene (18S or GAPDH).

\section{Immunohistochemical staining}

Subcutaneous Myc-CaP tumors were fixed with $10 \%$ formalin (Fisher Scientific, Pittsburgh, PA) for 3 days before paraffin embedding and sectioning. Five- $\mu \mathrm{m}$ sections were stained with hematoxylin and eosin, and anti-mouse CD3 (SP7; Thermo Fisher Scientific, Waltham, MA). Images were reviewed and interpreted by an experienced pathologist blinded to treatment arm (RAA).

\section{Flow cytometry}

Single-cell suspensions were prepared from dissected Myc-CaP tumors. Cells were stained with fluorochromeconjugated antibodies (BD Biosciences, San Diego, CA; BioLegend, San Diego, CA; eBiosciences, San Diego, CA) and analyzed using a LSR II flow cytometer (BD Biosciences, San Diego, CA). LIVE/DEAD aqua kits (Molecular Probes, Eugene, OR) or Fixable Viability Dye (eBiosciences, San Diego, CA) were used to exclude dead cells from analyses. The CTLA-4-positive population was assayed by both surface and intracellular staining. For intracellular staining, cells were fixed and permeabilized using fixation/permeabilization concentrate and diluent (eBiosciences, San Diego, CA) at room temperature for $30 \mathrm{~min}(60 \mathrm{~min}$ for FoxP3 staining). For intracellular cytokine staining, cells were stimulated for $4 \mathrm{~h}$ in the presence of protein transport inhibitor cocktail (eBiosciences, San Diego,
CA). Gates were set using matched isotype controls. For staining of cytokines and immune checkpoint molecules/ligands, cells were stimulated with CD3/ CD28 beads (Life Technologies, Oslo, Norway) for 3 days or phorbol myristate acetate (PMA; $50 \mathrm{ng} / \mathrm{ml}$ )/ ionomycin $(500 \mathrm{ng} / \mathrm{ml})$ for $4 \mathrm{~h}$. As a positive control for cytokine expression, ovalbumin (ova)-specific splenocytes (OT-1) were stimulated with OVA peptide $(5 \mathrm{ng} / \mathrm{ml})$ for 3 days; naive splenocytes were used as negative control. Data analysis was performed using the FlowJo software (Ashland, OR).

\section{Statistical analysis}

Statistical analysis was performed using Prism 6 (GraphPad, La Jolla, CA). Unpaired two-tailed $t$-tests or log-rank tests (for survival studies) were conducted and considered statistically significant at $P$-values $\leq 0.05(*), 0.01(* *)$, $0.001(* * *)$, and $0.0001(* * *)$.

\section{Results}

\section{Inflammation in the Myc-CaP model of castration sensitivity and resistance}

Because orchiectomy is an invasive procedure that might affect both local and systemic immunity, we tested whether the GnRH antagonist degarelix acetate could be used as an accurate model of castration in mice. Both orchiectomy and degarelix resulted in similar levels of testosterone on days 7 and 30 post-treatment (Supplemental Fig. 1). This similarity was reflected in a treatment setting; both degarelix and orchiectomy induced initial regression of established Myc-CaP tumors, followed by the emergence of castration-resistant disease (Fig. 1a). The emergence of castration resistance was defined as tumors that regressed post-ADT and subsequently grew again to a minimum volume of $420 \mathrm{~mm}^{3}$. Having established the similarity in degarelix and orchiectomy in reducing testosterone levels, we carried out the remainder of experiments using degarelix. We next tested whether ADT affected the expression of prostate-associated transcripts; as shown in Fig. 1b, message RNA-level expression of androgen receptor, Folhl (a prostate-specific membrane antigen analog), and Acpp (prostatic acid phosphatase) were increased postcastration. Psca (prostate stem cell antigen) expression was not significantly altered precastration and postcastration. Histologically, inflammation was apparent on day 7 after castration but was relatively sparse in precastration or castration-resistant tumors (Fig. 1c). Taken together, these results show that the subcutaneous Myc-CaP tumor model shares common 


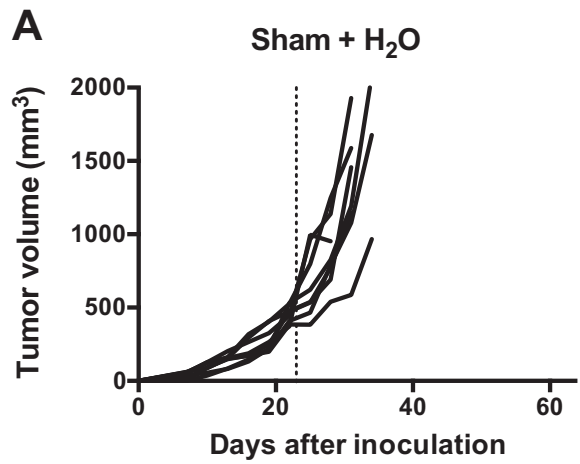

B

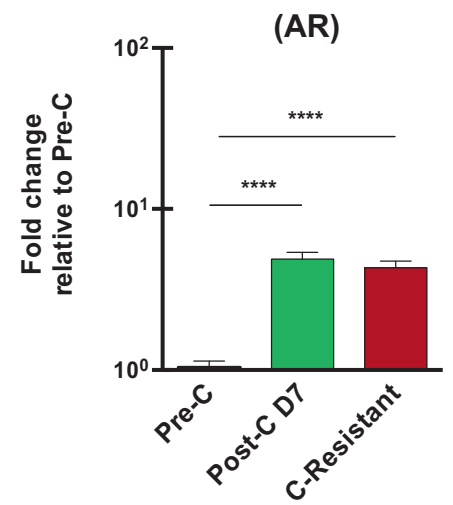

C

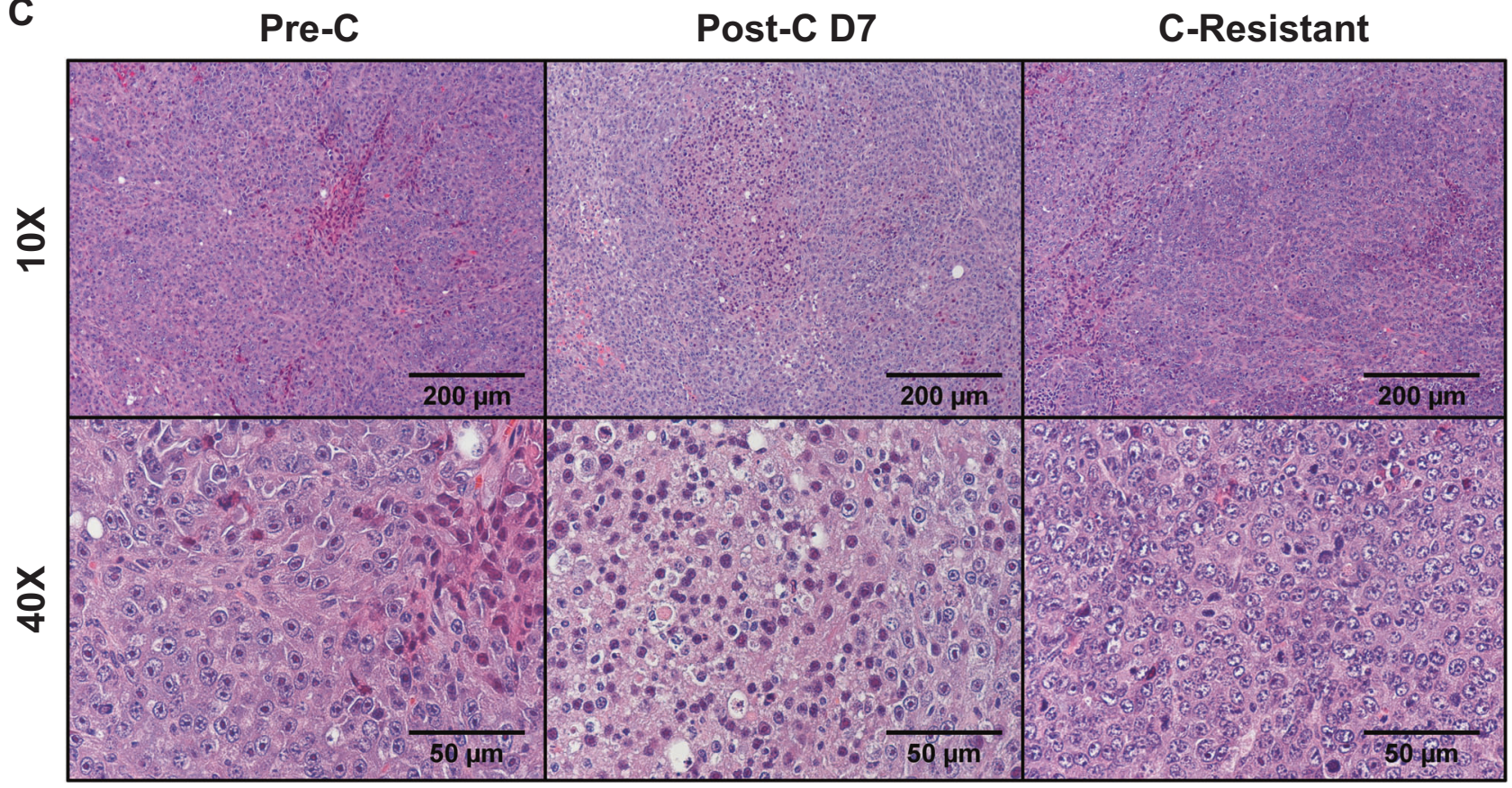

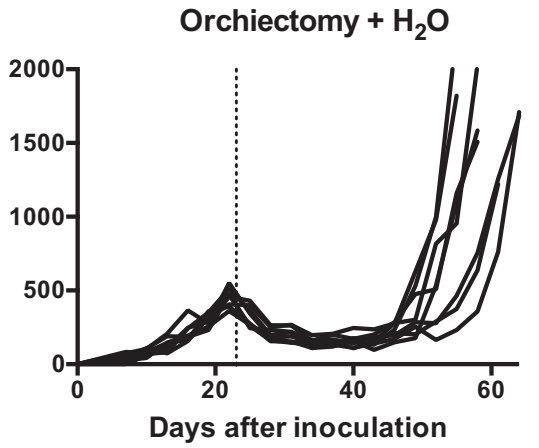

Folh1 (PSMA)

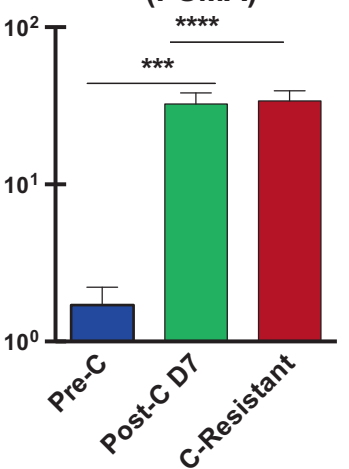

Acpp

(PAP)

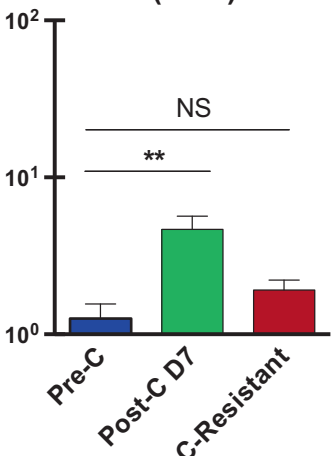

Sham + Degarelix

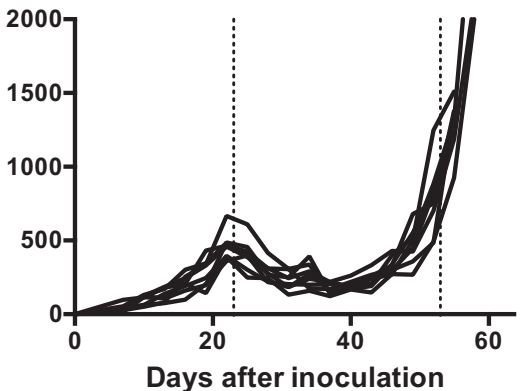

Psca

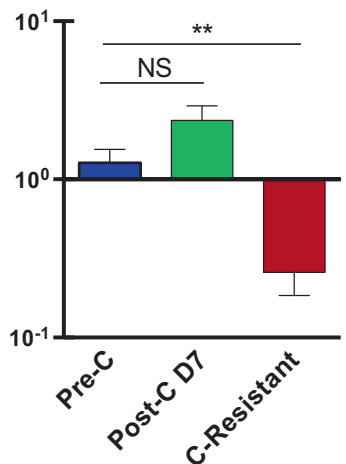

Fig. 1 Castration resistance and inflammation in the Myc-CaP model. Eight-week-old male FVB/NJ mice were inoculated with $1 \times 10^{6}$ cells Myc-CaP cells in the right flank; when mean tumor volume reached $420 \mathrm{~mm}^{3}$, mice were randomly assigned to treatment groups as shown $(n=8$ per group, repeated $3 \times)$. a Tumor growth curves-representative of at least three independent experiments. Vertical dashed line indicates time at which castration or control treatment was performed. $\mathbf{b}$ qPCR for selected androgen-associated transcripts; all data normalized to the precastration (Pre-C) group. Fold change calculated by $\Delta \Delta \mathrm{Ct}$, normalized to precastration counts (Pre-C). Reactions performed in triplicate, repeated $2 \times$. c Representative H\&E sections of the indicated tumors, magnification as shown. Data are mean \pm SEM. $P$-values determined by unpaired $t$-test or Mann-Whitney test. $* P<0.05 ; * * P<0.01$; NS, not statistically significant 
characteristics with human prostate cancer progression and has some evidence of immune infiltration early after castration.

\section{ADT induces a complex immune infiltrate}

To understand the composition of the immune infiltrate postcastration, we used quantitative PCR (qPCR) to evaluate the expression of cell-type markers, cytokines, transcription factors, immune checkpoint molecules, and ligands. We found that the expression of Ptprc (CD45), CD4, CD8a, Ncam1 (CD56; a natural killer cell marker), Adgre 1 (F4/80; a macrophage marker), Ifng (interferon gamma, IFN- $\gamma$ ), tnf (tissue necrosis factor- $\alpha$; TNF- $\alpha$ ), Tgfb1 (transforming growth factor- $\beta 1$; TGF- $\beta 1$ ), Il10 (interleukin-10; IL-10), Il6 (interleukin-6; IL-6), Tbx21 (Tbet), Gata3, Rorc (ROR- $\gamma$ ), Eomes, and FoxP3 were all significantly increased on day 7 postcastration (Fig. 2). Interestingly, many of these markers subsequently decreased to precastration levels with the development of castration resistance. Neither I14 (IL-4) nor I117 (IL-17) transcripts were detectable in Myc-CaP tumors (data not shown). These data suggest that castration increases tumor-infiltrating immune cells of various subsets, including CD4, CD8, and Tregs as well as natural killer (NK) cells and macrophages. The expression of the T-cell checkpoint molecule programmed cell death-1 (PD-1) and its ligands (PD-L1 and PD-L2), cytotoxic T lymphocyte antigen-4 (CTLA-4), lymphocyte activation gene-3 (LAG-3), and $\mathrm{T}$ cell immunoglobulin mucin-3 (TIM-3) were also significantly increased on day 7 postcastration but decreased in castration-resistant tumors. Taken together, these data reveal a complex, generally pro-inflammatory infiltrate early after castration and show that inflammation appears to partially resolve as castration resistance emerges.

\section{The immune TME evolves as castration resistance emerges}

To expand on those message RNA-level data, we used flow cytometry to determine the relative contribution of various immune cell types to the total CD45+ (bone marrow-derived) population. Intratumoral $\mathrm{CD} 4+\mathrm{T}$ cells, CD8 + T cells, Treg, B cells, NK cells, dendritic cells (DC), and macrophages were quantified as shown in Supplemental Fig. 2. Similar to the qPCR results, these data showed dynamic changes in immune cell subsets over time. For example, the percentage of NK cells (CD3-, $\mathrm{CD} 49 \mathrm{~b}+$ ) was significantly increased on day 7 after castration and then significantly decreased as castration resistance emerged (Fig. 3a). The percentage of macrophages $(\mathrm{CD} 11 \mathrm{~b}+, \mathrm{F} 4 / 80+)$ was significantly increased on day 7 after castration and continued to increase as castration resistance emerged (Fig. 3b). The percentage of DCs $(\mathrm{CD} 11 \mathrm{~b}-, \mathrm{CD} 11 \mathrm{c}+)$ was progressively decreased during the development of castration resistance (Fig. 3b). The percentages of CD4 $+\mathrm{T}$ cells $(\mathrm{CD} 3+, \mathrm{CD} 4+, \mathrm{CD} 8-)$ and $\mathrm{B}$ cells (CD3-, CD19+) were significantly decreased on day 7 after castration but then returned to near precastration levels. By contrast, the percentage of CD8 $+\mathrm{T}$ cells $(\mathrm{CD} 3+, \mathrm{CD} 4-, \mathrm{CD} 8+)$ was not significantly changed during the development of castration resistance. Notably, $39.5 \pm 5.7 \%$ of tumor-infiltrating CD4 $+\mathrm{T}$ cells were Treg $(\mathrm{CD} 4+$, FoxP3 +$)$ on day 7 after castration vs. $23.7 \pm 2.5 \%$ before castration and $13.4 \pm 7.5 \%$ when castration resistance had emerged. Alterations in these immune cell populations are also shown as the number of cells per gram of tumor in Supplemental Fig. 3. The evolving composition of the immune infiltrate in the TME is summarized in Fig. 3c, highlighting the finding that the percentage of $\mathrm{CD} 11 \mathrm{~b}+$ cells increased progressively over time. In addition, these data suggest that Treg-directed immunotherapy might be most active in the early postcastration time period.

\section{Immune activation in the early postcastration setting}

To assess T-cell activation, we determined cytokine production by tumor-infiltrating $\mathrm{CD} 4+$ and $\mathrm{CD} 8+\mathrm{T}$ cells using flow cytometry. For these experiments, raw flow data are shown in Supplementary Figures 4-8 and summarized in Fig. 4a. Castration significantly increased TNF- $\alpha$ and IL-2 production by conventional CD4+ T cells on day 7 after castration (Fig. 4a). Similarly, castration also dramatically increased IFN- $\gamma$, TNF- $\alpha$, IL-2, and granzyme B production by CD8 $+\mathrm{T}$ cells (Fig. $4 \mathrm{a}$ ). For both $\mathrm{CD} 4+$ and $\mathrm{CD} 8+\mathrm{T}$ cells, cytokine production returned to baseline levels as castration resistance emerged.

We next explored cell-level expression of immune checkpoint molecules on CD4 and CD8 T cells during the progression to castration resistance. As shown in Fig. 4b, castration significantly increased CD4+ T-cell expression of PD-1 and CTLA-4 but not of LAG-3 or TIM-3. By contrast, castration did not significantly increase the expression of PD1 or CTLA- 4 on CD8+ T cells. PD- 1 and CTLA-4 can be co-expressed on $\mathrm{CD} 4+$ or $\mathrm{CD} 8+\mathrm{T}$ cells-as shown in Supplemental Fig. 8, castration significantly increased the percentage of PD-1+ CTLA-4+ CD4 $+\mathrm{T}$ cells. Interestingly, the frequencies of immune checkpoint-expressing tumor-infiltrating CD4+ and CD8 + T cells in castrationresistant tumors were generally lower than those observed prior to castration. Taken together, these data suggest that immune checkpoint blockade might prove most efficacious when applied in the early postcastration time period. 


\section{A. Cell-type markers}

Ptprc

(CD45)

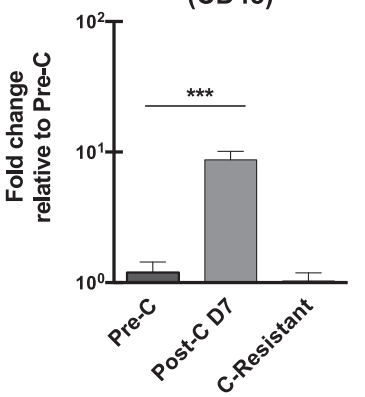

Itgam

(CD11b)

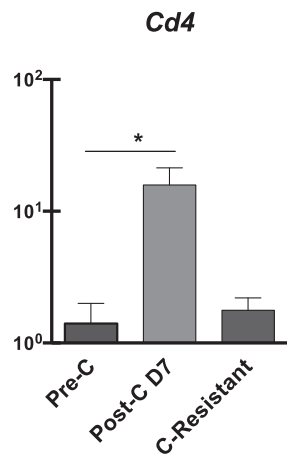

Itgax

(CD11c)
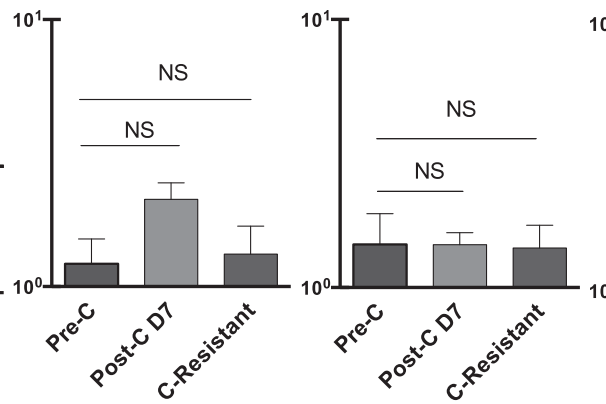

Cd8a

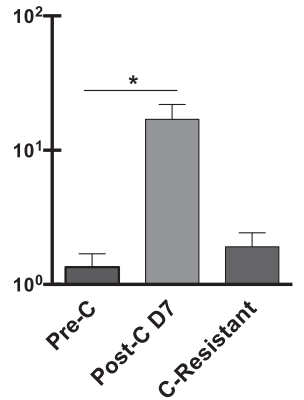

MS4a1

(CD20)
Ncam1

(CD56)

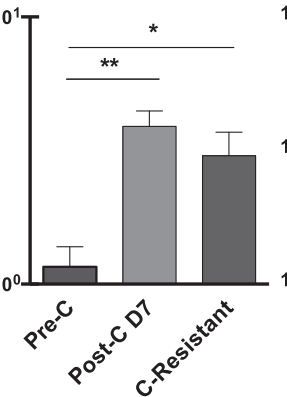

Adgre1

(F4/80)

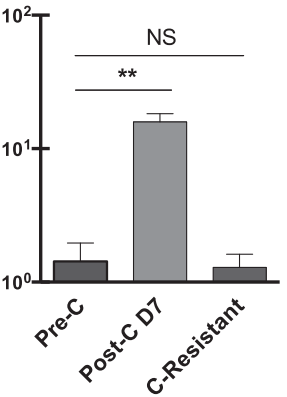

\section{B. Cytokines}
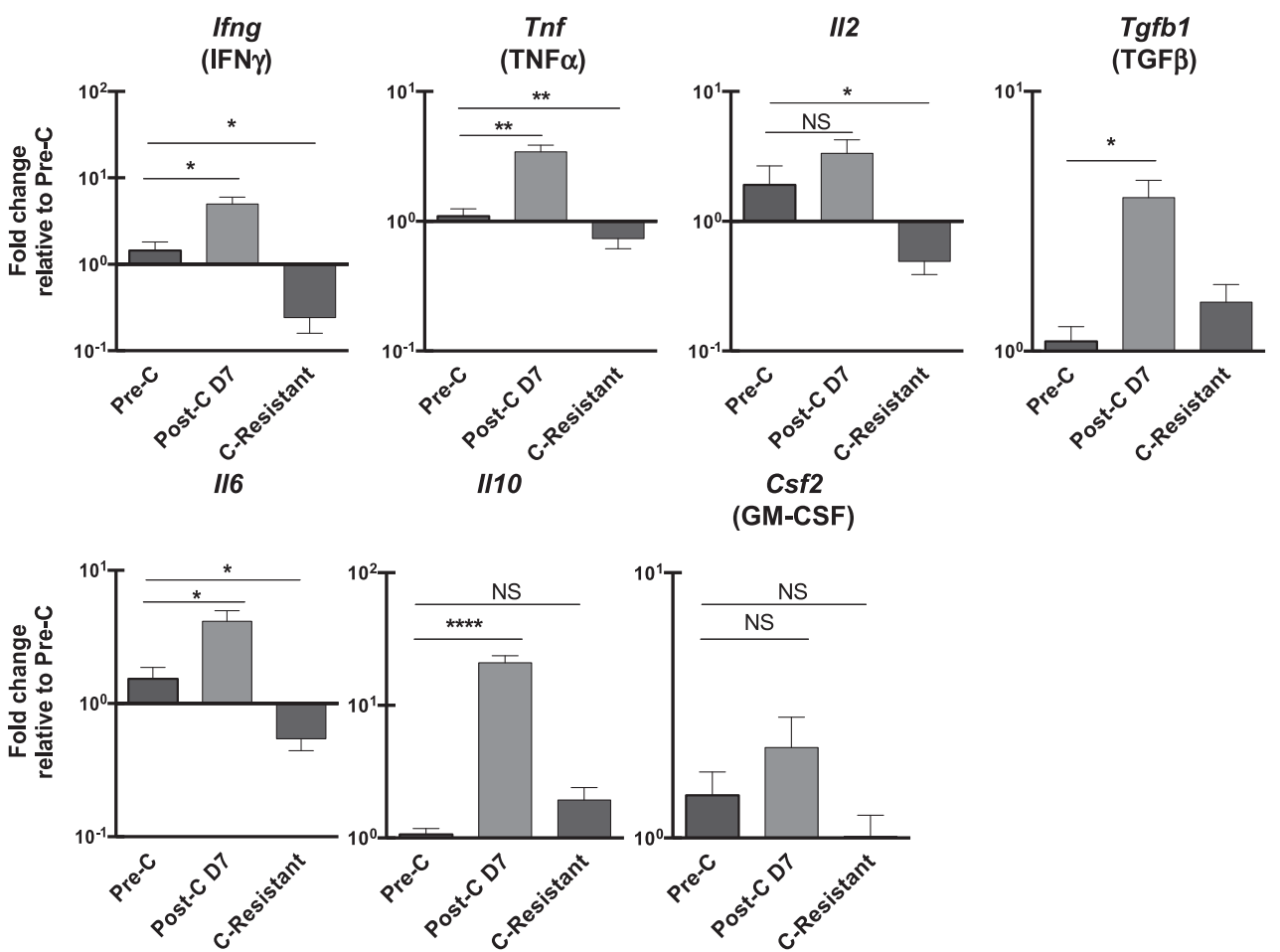

Fig. 2 Transcript-level evaluation of the immune components of the postcastration tumor microenvironment (TME). Bulk tumor samples from animals treated as in Fig. 1 analyzed by qPCR using the indicated probe sets. Fold change calculated by $\Delta \Delta \mathrm{Ct}$, normalized to Pre-C. Reactions performed in triplicate, repeated $2 \times$. a
Transcripts associated with immune cell subsets. b Cytokines. c Immunologically relevant transcription factors. d Immune checkpoints and ligands. Data are mean \pm SEM. $P$-values determined by unpaired $t$-test, $* P<0.05 ; \quad * * P<0.01 ; \quad \mathrm{NS}$, not statistically significant 


\section{Transcription factors}

Gata3

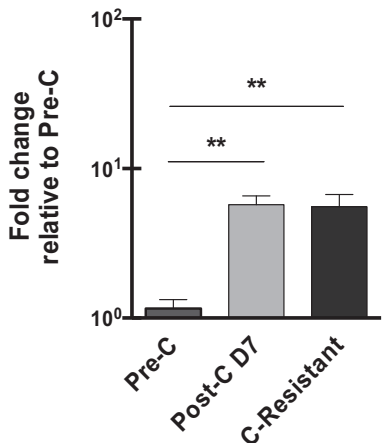

Rorc

$(\mathrm{ROR} \gamma)$

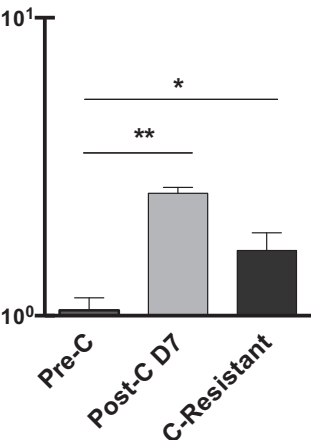

Eomes

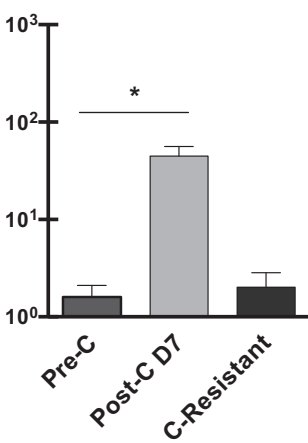

$T b \times 21$

(T-bet)
Foxp3

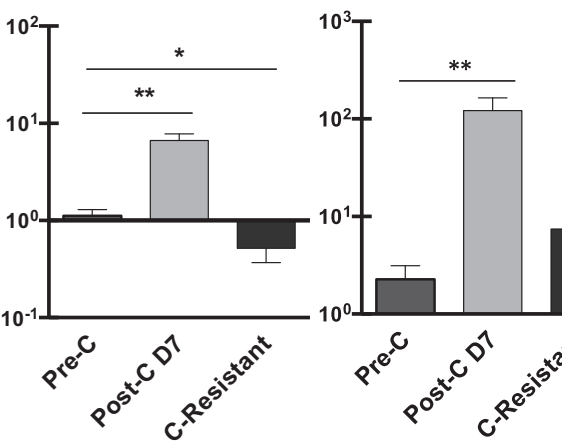

D. Immune checkpoint molecules and ligands

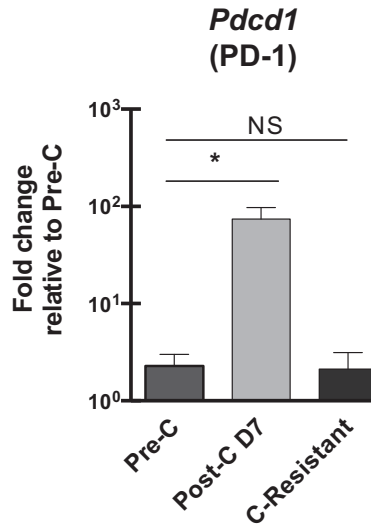

Lag3
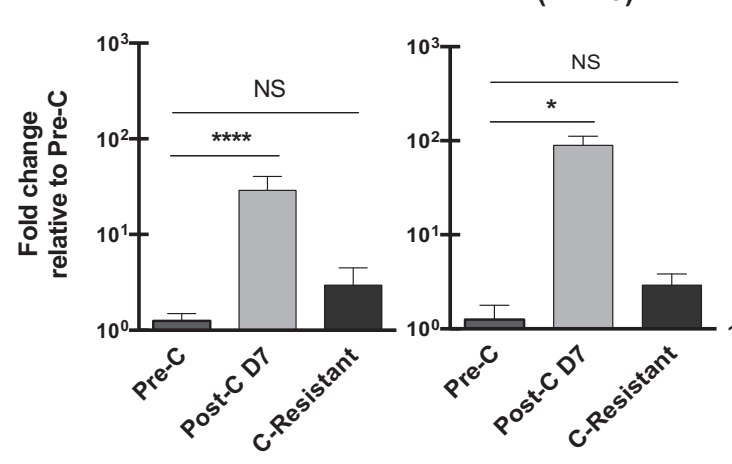

Havcr2
(TIM-3)

Havcr2
(TIM-3)

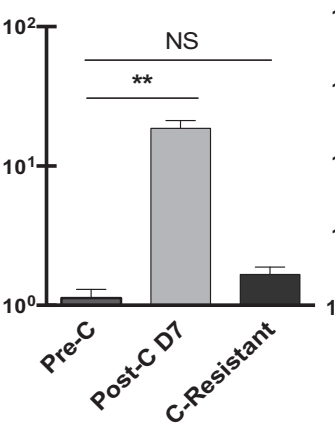

Fig. 2 (continued)

\section{Treg depletion in the peri-castration period shows preclinical activity}

Based on the findings above, we tested the hypothesis that either PD-1 blockade and/or Treg depletion would show preclinical activity when administered peri-castration. As shown in Fig. 5, mice were treated with ADT alone or in
Ctla4 (CTLA-4)

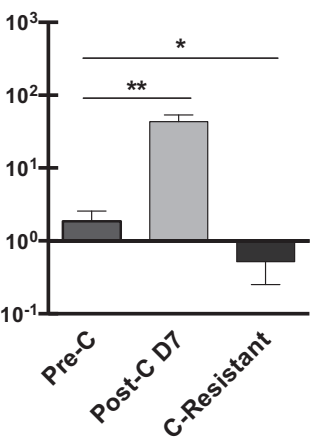

Pdcd1/g2

(PD-L2)

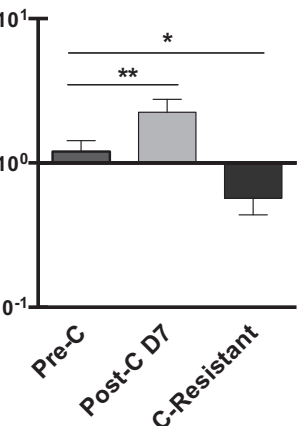
depleting antibody (IgG2a isotype, (D)) [18] or a nondepleting antibody (IgG1 isotype, (ND)). Three treatment doses were administered every other day, starting the day of ADT. As shown in Fig. 5a, degarelix plus $\alpha$ CTLA-4 (D) or degarelix plus $\alpha$ PD-1 plus $\alpha$ CTLA-4 (D) reduced tumor outgrowth and delayed the emergence of progressive 

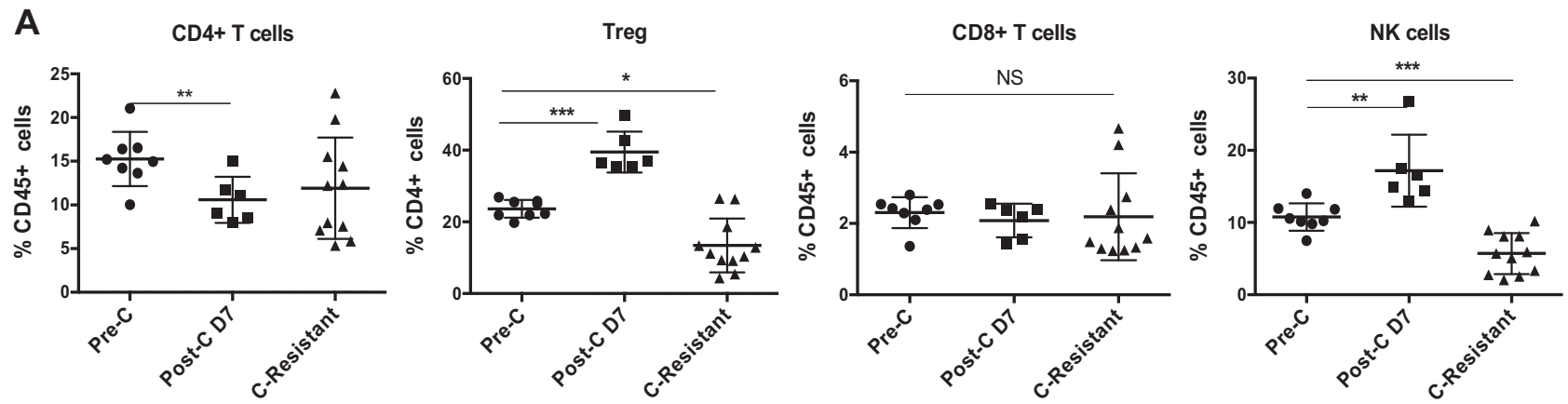

B

B cells
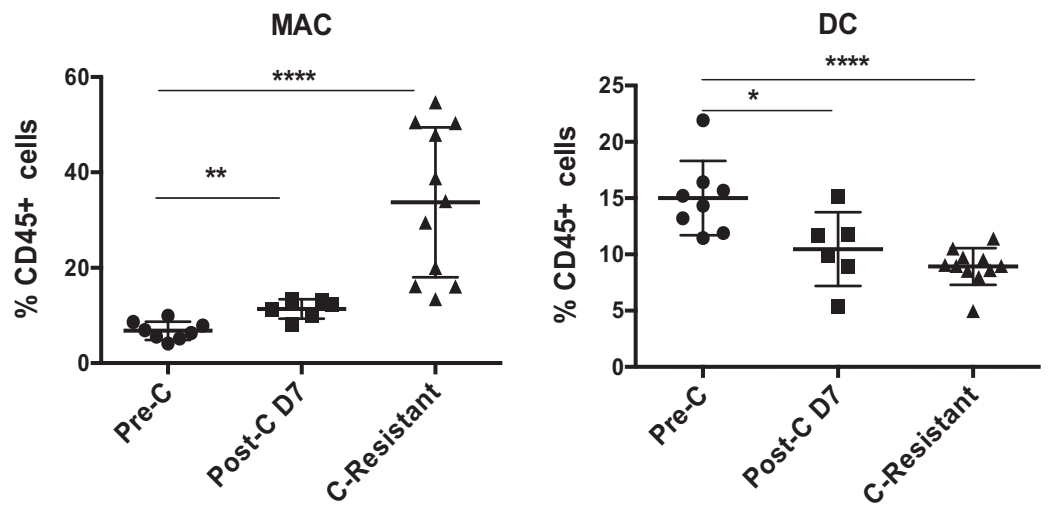

C

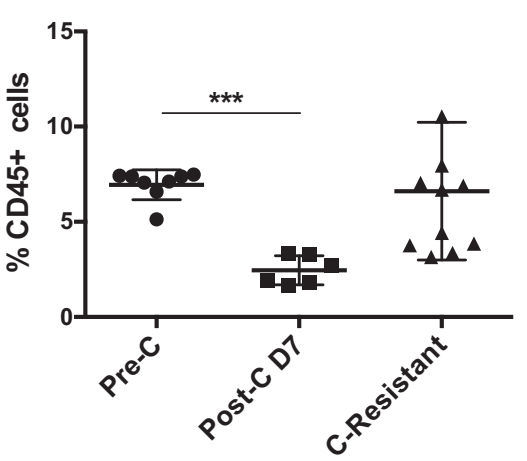

Pre-C

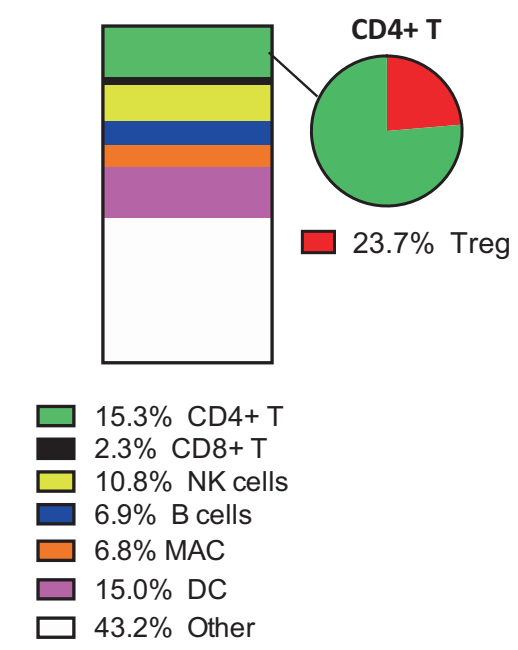

Post-C D7

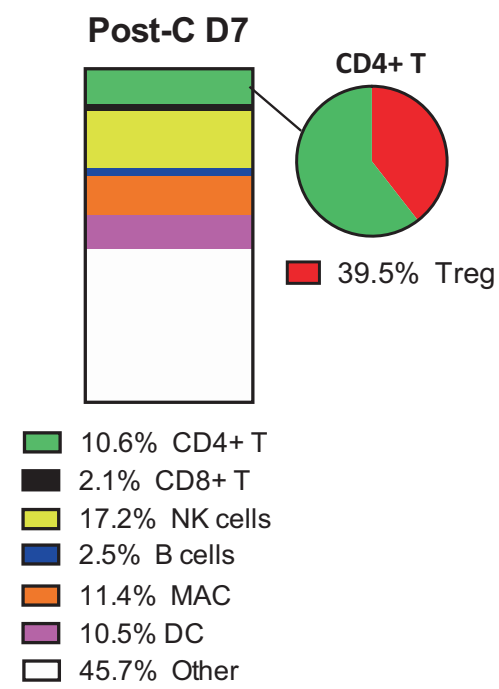

C-Resistant

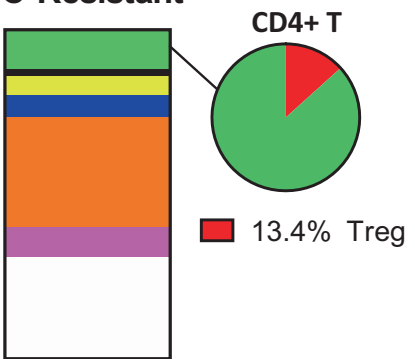

$11.9 \% \mathrm{CD} 4+\mathrm{T}$

$2.2 \% \mathrm{CD} 8+\mathrm{T}$

$5.7 \%$ NK cells

$6.6 \%$ B cells

$\square 33.7 \%$ MAC

$\square .9 \% \mathrm{DC}$

$31.0 \%$ Other

Fig. 3 Flow cytometry (protein-level) quantification of the cellular immune components of the postcastration tumor microenvironment (TME). Singlecell suspensions of resected tumors before castration (Pre-C), day 7 after castration (Post-C D7), and upon development of castration resistance (C-Resistant) analyzed by flow cytometry. Data are representative of at least 3 independent experiments, with 5-8 animals per group. a T-cell

castration-resistant disease. While both degarelix $+\alpha$ CTLA4 (D) and degarelix $+\alpha$ PD-1 $+\alpha$ CTLA- 4 (D) significantly enhanced survival, the addition of $\alpha \mathrm{PD}-1$ to degarelix + $\alpha$ CTLA-4 (D) did not significantly improve OS. This populations as a percentage of CD45+ cells in the TME. Note that Treg are shown as a percentage of CD45+/CD4+ cells for clarity. b Additional populations of interest: note that here macrophages (MAC) are defined as CD45 cells that are CD11b+ F4/80+ . c Summary data with Treg as a percentage of CD4 expanded for clarity. $* P<0.05$; $* * P<0.01$; $* * * P<$ 0.001 ; and $* * * * P<0.0001 ; \mathrm{NS}$, not statistically significant

experiment was repeated $2 \times$; in both iterations, several animals in the mice treated with degarelix plus $\alpha$ CTLA-4 (D) showed long-term survival ( $>7$ months). In addition, $\alpha$ CTLA-4 (D) was well tolerated without gross evidence of 

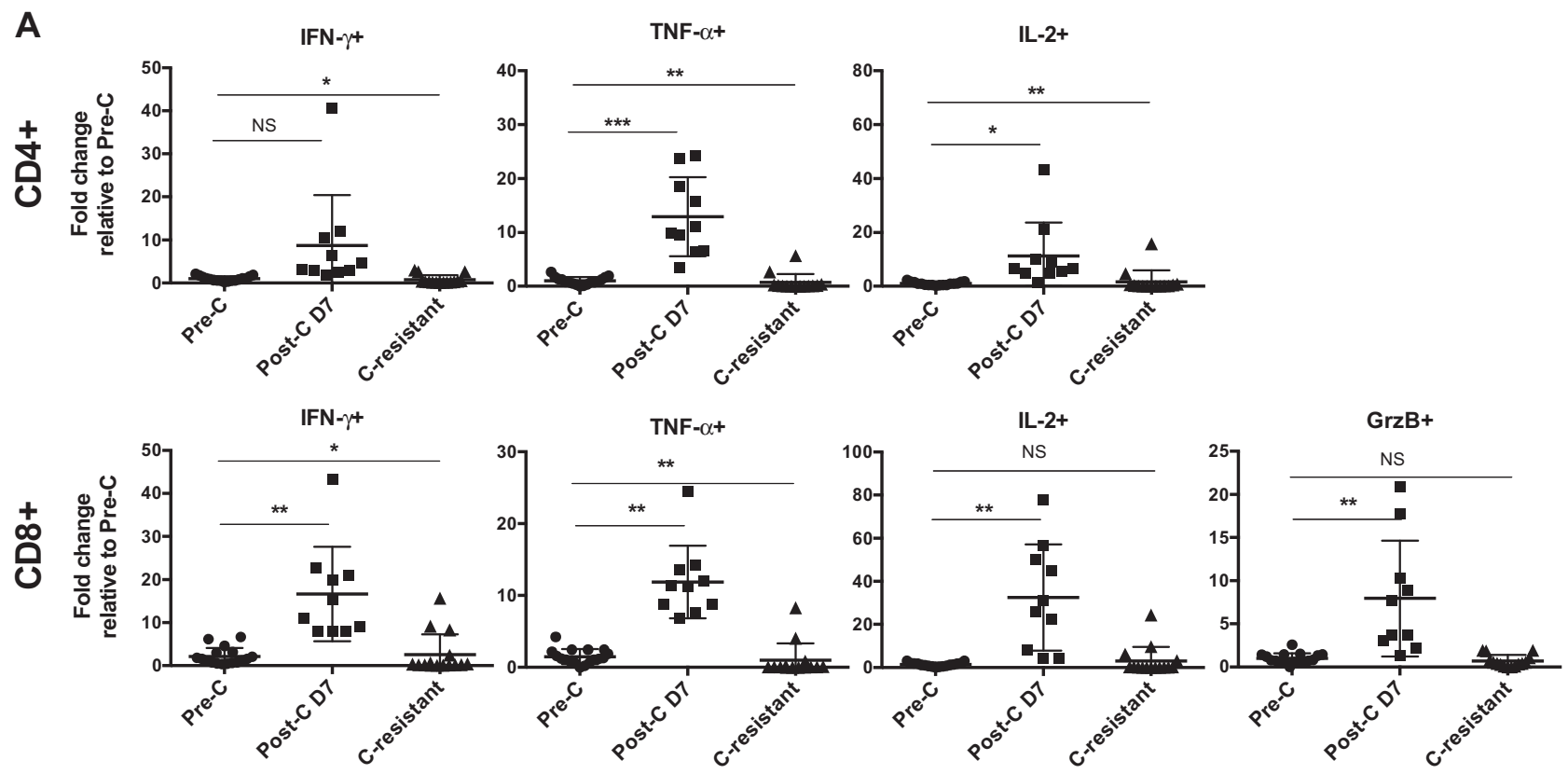

B
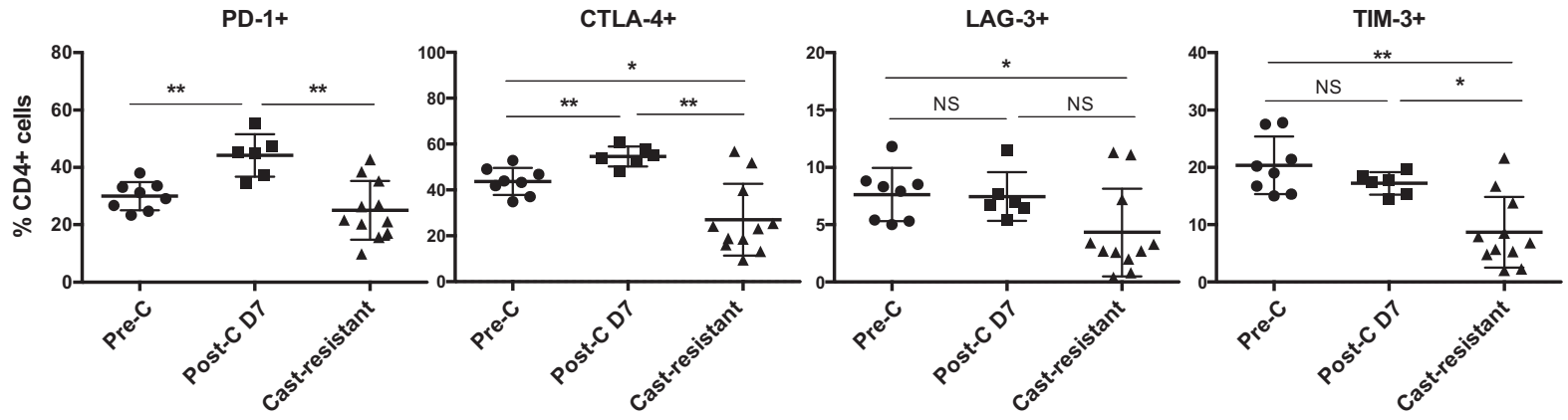

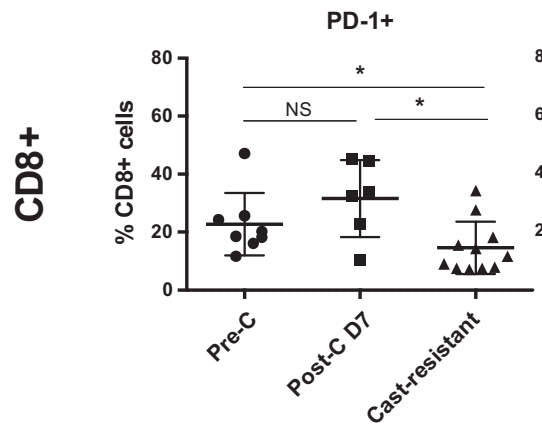

Fig. 4 Expression of effector cytokines and immune checkpoint molecules in the postcastration TME. Single-cell suspensions of resected tumors before castration (Pre-C), day 7 after castration (Post-C D7), and upon development of castration resistance (C-Resistant). For cytokine analyses, cells were stimulated ex vivo with PMA and ionomycin for $4 \mathrm{~h}$ and expression quantified by flow cytometry. Data are representative of at least 3 independent
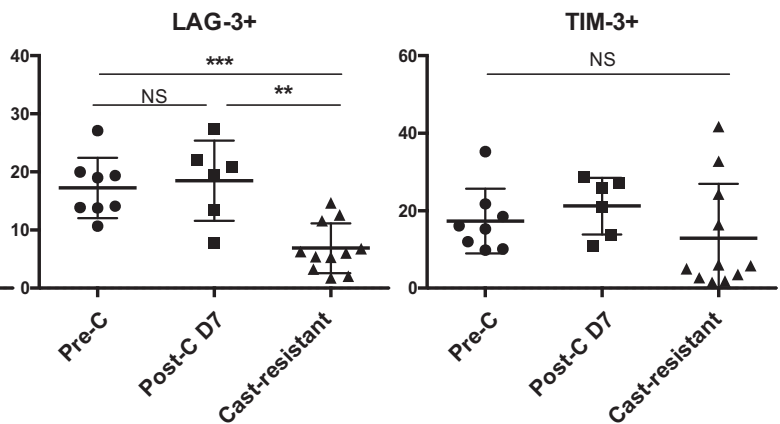

experiments, with 5-8 animals per group. a Cytokine expression on tumor infiltrating $\mathrm{T}$ cells. b Expression of immune checkpoint molecules on tumor-infiltrating $\mathrm{T}$ cells as assessed by flow cytometry, note these samples were not stimulated prior to staining. Data are representative of two independent experiments and are shown as mean $\pm \mathrm{SD}$. GrzB, granzyme $\mathrm{B} ; * P<0.05 ; * * P<0.01$; $* * * P<$ $0.001 ; \mathrm{NS}$, not statistically significant

weight loss, skin changes, or other autoimmune pathology. These preclinical effects were reflected at the histological level, with an increased inflammatory (Fig. 5c) and T-cell (Fig. 5d) infiltration apparent in mice treated with the $\alpha$ CTLA-4 (D) agent. Flow cytometric evaluation of the tumor-infiltrating lymphocytes (TILs) from treated mice (Figs. 5e-h) showed increased IFN- $\gamma$ production from the CD4 and CD8 TILs in mice treated with the depleting antibody. Interestingly, Treg depletion was significant as a percentage of CD4 $\mathrm{T}$ cells but was not significant as a 


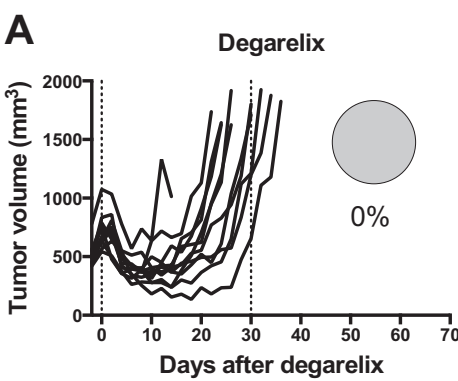

Degarelix $+\alpha$ PD-1

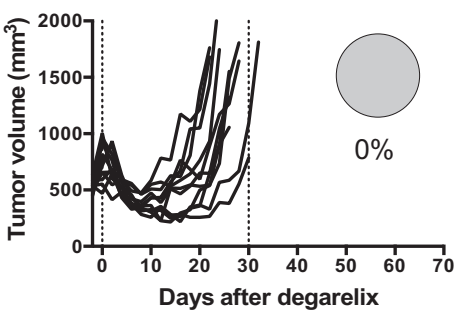

B

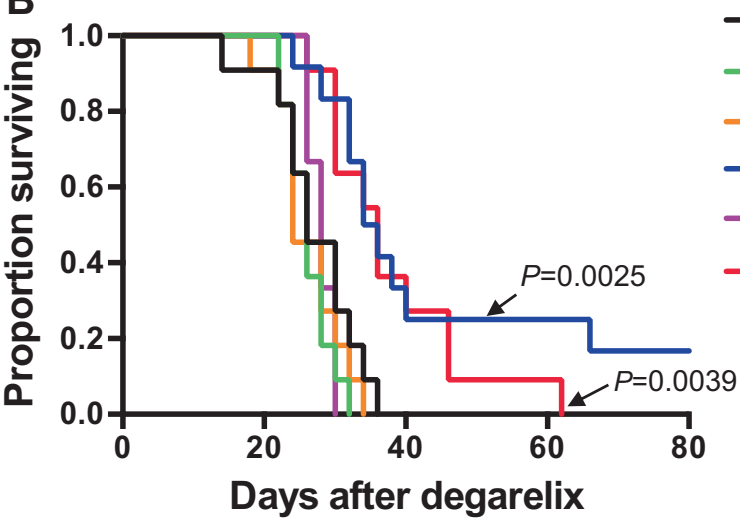

C

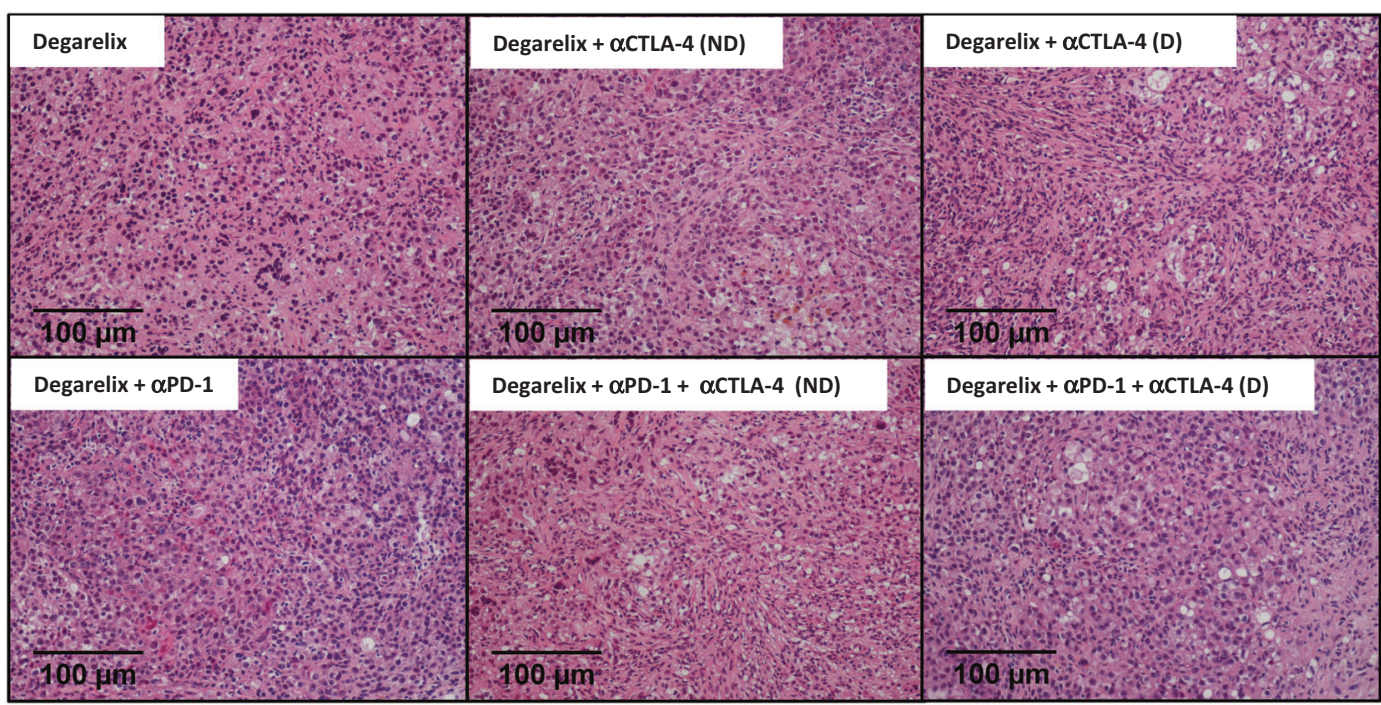

Fig. 5 Combining $\alpha$ CTLA-4(D) with ADT prolongs survival. Eight weekold FVB/NJ male mice were subcutaneously inoculated with $1 \times 10^{6}$ MycCap cells and treated as indicated. $N=10$ animals per group, repeated $1 \times$. a Individual tumor growth. Pie chart shows the proportion of complete responses (blue). b Overall survival from time of ADT. $P$-values determined by Log-rank (Mantel-Cox) test in comparison with degarelix alone. c Representative $\mathrm{H} \& \mathrm{E}$ sections from treatment groups as indicated. SPRINGER NATURE
Magnification $\times 20$. d Representative IHC images of anti-CD3-stained tumors. Magnification $\times 20$. e, f Cytokine production by infiltrating CD4 and CD8 $\mathrm{T}$ cells, respectively. $\mathbf{g}$ Treg percentages as a percentage of total CD45 TIL and CD4 TIL, respectively. h CD4 and CD8 effector-to-Treg ratios, effector defined as IFN $-\gamma+$ Data shown as mean \pm SD. $* P<0.05 ; * * P<0.01$; $* * * P<0.001$; NS, not statistically significant. A full color version of this figure is available at the Prostate Cancer and Prostatic Diseases journal online 
D

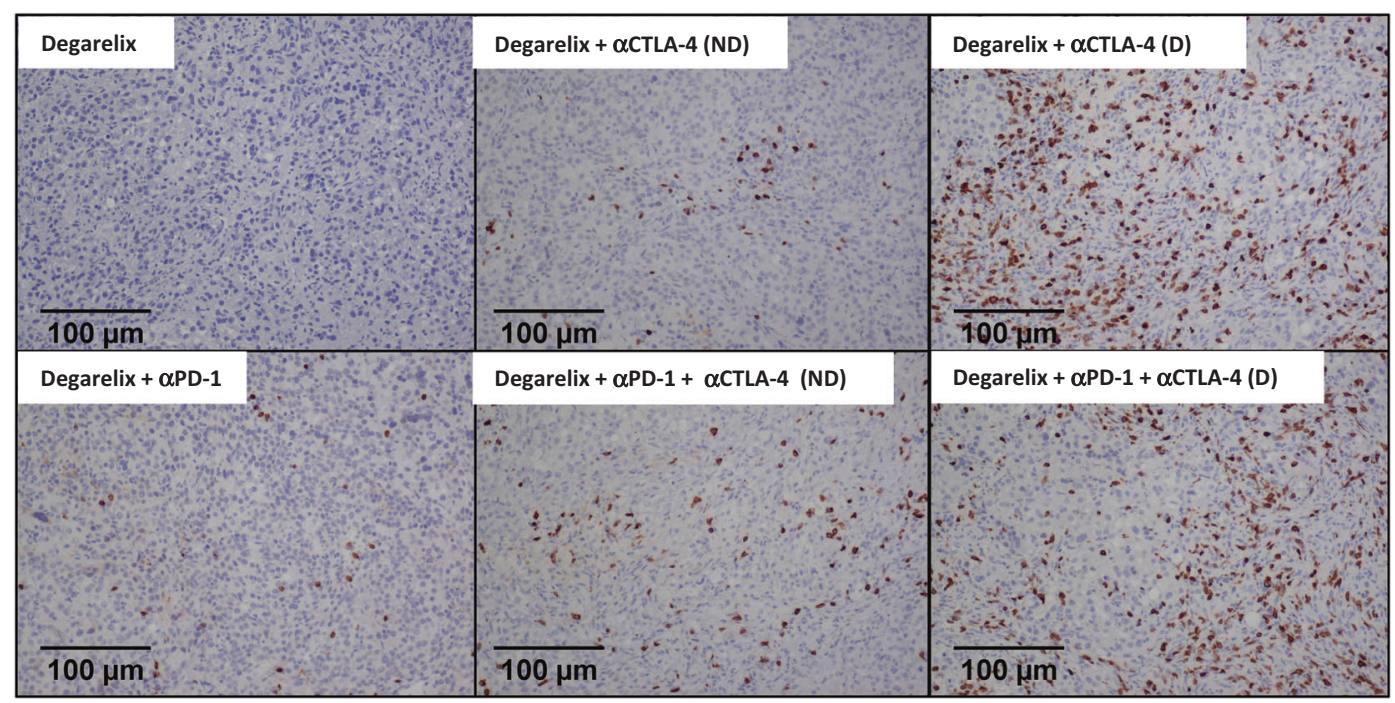

E
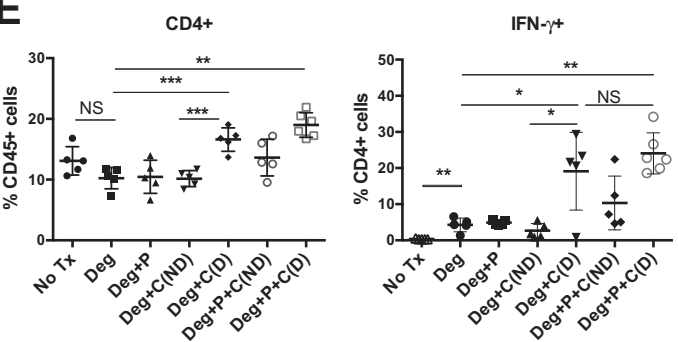

G
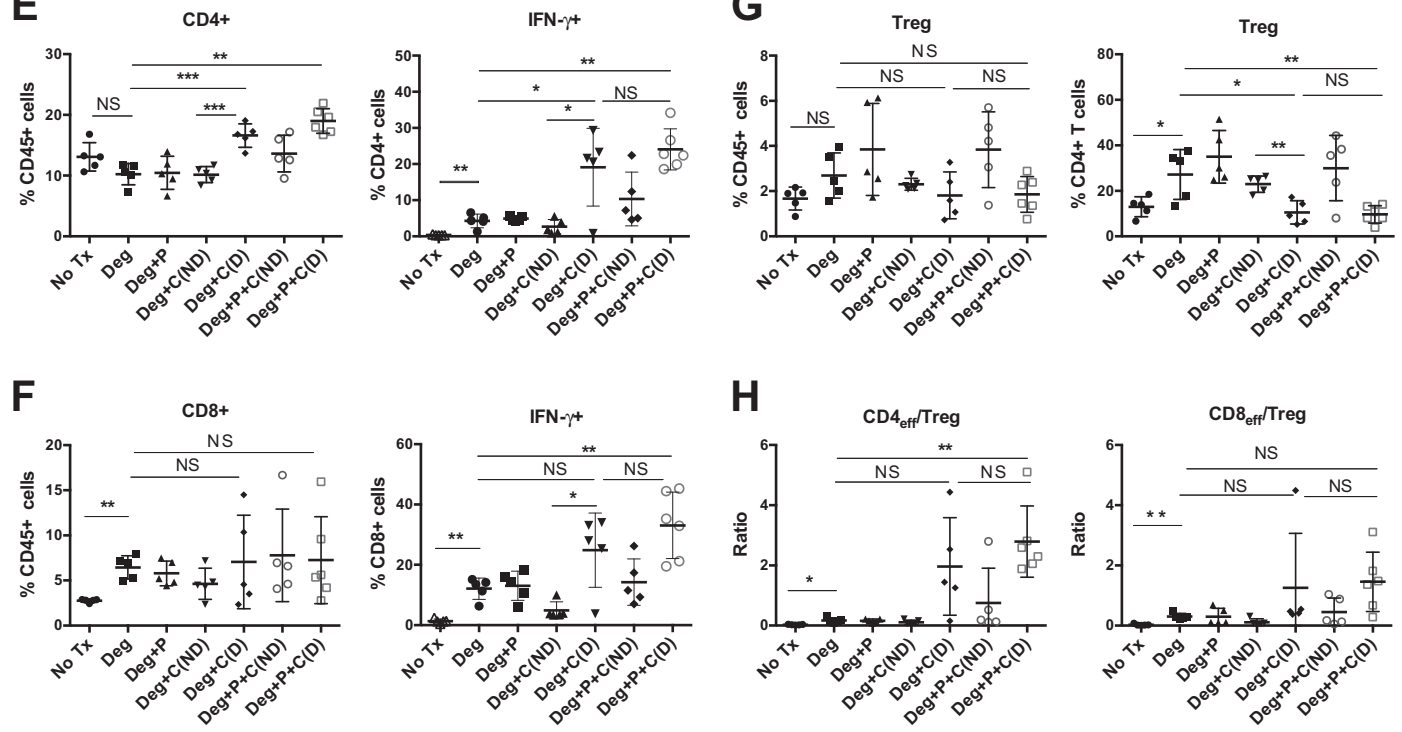

H
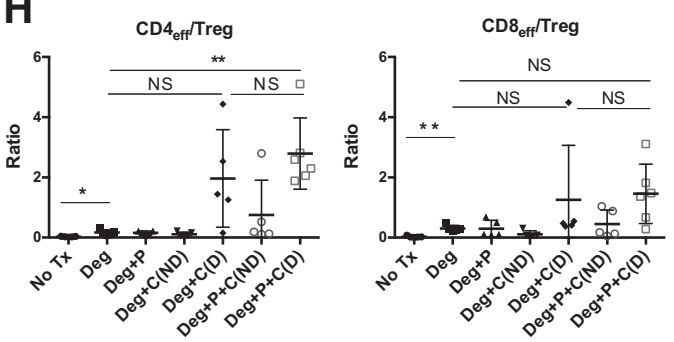

Fig. 5 (continued)

percentage of the total CD45+ TILs (Fig. $5 \mathrm{~g}$ ) and was not reflected as a significant change in Teff (CD4+ Foxp3cells) to CD8 ratio (Fig. 5h). Further, Treg depletion was specific to the TIL compartment, as shown in Supplemental Fig. 9, and the prevalence of Treg in the tumor-draining lymph nodes and spleen were not affected by $\alpha$ CTLA-4(D) treatment. Supplemental Fig. 10 demonstrates representative flow cytometry data on Treg frequency and cytokine expression by CD4 and CD8 TILs as a function of treatment group. Overall, these preclinical studies support Treg depletion in the peri-castration period and suggest that the addition of anti-PD-1 may not be additive in this setting.

\section{Treatment is not effective in the absence of ADT}

To investigate whether ADT was required for the activity seen in Fig. 5a, we performed similar studies in either castration-sensitive Myc-CaP tumors or in tumors that progressed after initial androgen ablation. Antibody treatment was identical to that administered in combination with degarelix, and a total of 3 doses of $10 \mathrm{mg} / \mathrm{kg}$ were given every other day. As shown in Supplemental Fig. 11A, treatment of castration-sensitive disease with either $\alpha$ CTLA-4(D) or $\alpha$ CTLA-4(D) plus $\alpha$ PD-1 was ineffective. Similarly (Supplemental Fig. 11B), late treatment of emerging castration-resistant disease was also ineffective. 


\section{Discussion}

ADT is a standard treatment for recurrent or metastatic prostate cancer; however, fatal castration-resistant disease ultimately emerges in the majority of patients. Using the Myc-CaP model, we investigated the immunological consequences of ADT over time, with a particular interest in changes occurring as castration resistance emerges. Similar to prior studies in patients $[11,12]$, we found that ADT is initially pro-inflammatory with a mixed $\mathrm{T}$ cell, Treg, macrophage, and NK cell infiltrate. However, as castration resistance emerged, the composition of the infiltrate evolved, with CD11b + cells becoming increasingly dominant and effector T-cell populations waning. These data are broadly consistent with prior human studies but add an additional dimension in terms of timing.

Interestingly, CD4+ Treg appeared to be a fairly prevalent population in the early postcastration time period. Based on that finding, and on the increased expression of immune checkpoint molecules at that time point, we performed treatment studies in the peri-castration period. We found that, similar to human prostate cancer, Myc-CaP tumors were challenging to treat immunologically, with only the combination of ADT and a Treg-depleting $\alpha C$ TLA-4 antibody showing significant treatment effects. The depleting activity of IgG2a antibodies has been shown to be dependent on engagement of the activatory $\mathrm{Fc}$ receptor FCGR4 [22]. We hypothesize that the depleting activity seen in the early postcastration period is likely due to the recruitment of macrophages to the TME after ADT. Macrophages express the highest levels of FCGR4 [23] within the TME and this may explain why depleting $\alpha$ CTLA- 4 does not have efficacy in the absence of ADT. While perhaps disappointing, these studies are not incompatible with human clinical trial data; anti-CTLA-4 treatment (ipilimumab) was unsuccessful in two randomized Phase III clinical trials in castration-resistant disease. Although infiltrating T cells express PD-1 postcastration, adding blockade to ADT was not active here, suggesting that the suppressive activity of Treg is likely dominant in this model. The lack of significant efficacy of anti-PD-1 in the Phase Ib trial of nivolumab is also broadly consistent with our findings. It is noteworthy, however that a recent study showed interesting activity of the anti-PD-1 antibody pembrolizumab in patients with metastatic castrationresistant prostate cancer progressing on the second-line anti-androgen enzalutamide. Those results suggest that the post-enzalutamide TME might be different from that encountered in other settings, as suppported by data showing increased PD-L1 expression on the DC of patients with enzalutamide progression [24].
Taken together, our data support immunological treatment in the peri-castration period and suggest that a deeper understanding of the immunological TME in that setting could lead to improved combination treatment regimens for castration-sensitive prostate cancer.

Acknowledgements The authors thank Ms. Muniza Uddin and Dr. Alan Meeker for assistance with immunohistochemistry.

Financial support A.G. was supported by NIH T32GM007309. C.G.D. was supported by NIH R01CA127153, the Patrick C. Walsh Prostate Cancer Research Fund, the One-in-Six Foundation, the Prostate Cancer Foundation, and the Melanoma Research Alliance

\section{Compliance with ethical standards}

Conflicts of interest C.G.D. has served as a paid consultant to Agenus, Bristol Myers Squibb, Compugen, Dendreon, Merck, and Roche Genentech and has received sponsored research funding (institutional) from Bristol Myers Squibb under the International Immuno-Oncology Network (IIoN). A.K. and M.J.S. are paid employees of Bristol Myers Squibb. The other authors declare that they have no competing interests.

Open Access This article is licensed under a Creative Commons Attribution-NonCommercial-NoDerivatives 4.0 International License, which permits any non-commercial use, sharing, distribution and reproduction in any medium or format, as long as you give appropriate credit to the original author(s) and the source, and provide a link to the Creative Commons license. You do not have permission under this license to share adapted material derived from this article or parts of it. The images or other third party material in this article are included in the article's Creative Commons license, unless indicated otherwise in a credit line to the material. If material is not included in the article's Creative Commons license and your intended use is not permitted by statutory regulation or exceeds the permitted use, you will need to obtain permission directly from the copyright holder. To view a copy of this license, visit http://creativecommons.org/licenses/by-nc-nd/4.0/.

\section{References}

1. Topalian SL, Drake CG, Pardoll DM. Immune checkpoint blockade: a common denominator approach to cancer therapy. Cancer Cell 2015;27:450-61.

2. Callahan MK, Postow MA, Wolchok JD. Targeting T cell coreceptors for cancer therapy. Immunity 2016;44:1069-78.

3. Slovin SF, Higano CS, Hamid O, Tejwani S, Harzstark A, Alumkal JJ, et al. Ipilimumab alone or in combination with radiotherapy in metastatic castration-resistant prostate cancer: results from an open-label, multicenter phase I/II study. Ann Oncol. 2013;24:1813-21.

4. Kwon ED, Drake CG, Scher HI, Fizazi K, Bossi A, van den Eertwegh AJ, et al. Ipilimumab versus placebo after radiotherapy in patients with metastatic castration-resistant prostate cancer that had progressed after docetaxel chemotherapy (CA184-043): a multicentre, randomised, double-blind, phase 3 trial. Lancet Oncol 2014;15:700-12.

5. Beer TM, Kwon ED, Drake CG, Fizazi K, Logothetis C, Gravis $\mathrm{G}$, et al. Randomized, double-blind, phase III trial of ipilimumab versus placebo in asymptomatic or minimally symptomatic 
patients with metastatic chemotherapy-naive castration-resistant prostate cancer. J Clin Oncol 2017;35:40-7.

6. Topalian SL, Hodi FS, Brahmer JR, Gettinger SN, Smith DC, McDermott DF, et al. Safety, activity, and immune correlates of anti-PD-1 antibody in cancer. N Engl J Med 2012;366:2443-54.

7. Graff JN, Alumkal JJ, Drake CG, Thomas GV, Redmond WL, Farhad M, et al. Early evidence of anti-PD-1 activity in enzalutamide-resistant prostate cancer. Oncotarget 2016; 7:52810-7.

8. Denmeade SR, Isaacs JT. A history of prostate cancer treatment. Nat Rev Cancer 2002;2:389-96.

9. Chen Y, Sawyers CL, Scher HI. Targeting the androgen receptor pathway in prostate cancer. Curr Opin Pharmacol 2008;8:440-8.

10. Furuya Y, Lin XS, Walsh JC, Nelson WG, Isaacs JT. Androgen ablation-induced programmed death of prostatic glandular cells does not involve recruitment into a defective cell cycle or p53 induction. Endocrinology 1995;136:1898-906.

11. Mercader M, Bodner BK, Moser MT, Kwon PS, Park ES, Manecke RG, et al. T cell infiltration of the prostate induced by androgen withdrawal in patients with prostate cancer. Proc Natl Acad Sci USA 2001;98:14565-70.

12. Gannon PO, Poisson AO, Delvoye N, Lapointe R, Mes-Masson AM, Saad F. Characterization of the intra-prostatic immune cell infiltration in androgen-deprived prostate cancer patients. J Immunol Methods 2009;348:9-17.

13. Ammirante M, Luo JL, Grivennikov S, Nedospasov S, Karin M. B-cell-derived lymphotoxin promotes castration-resistant prostate cancer. Nature 2010;464:302-5.

14. Drake CG, Jaffee E, Pardoll DM. Mechanisms of immune evasion by tumors. Adv Immunol 2006;90:51-81.

15. Sfanos KS, Bruno TC, Maris CH, Xu L, Thoburn CJ, DeMarzo AM, et al. Phenotypic analysis of prostate-infiltrating lymphocytes reveals TH17 and Treg Skewing. Clin Cancer Res 2008;14:3254-61.
16. Wada S, Yoshimura K, Hipkiss EL, Harris TJ, Yen HR, Goldberg $\mathrm{MV}$, et al. Cyclophosphamide augments antitumor immunity: studies in an autochthonous prostate cancer model. Cancer Res 2009;69:4309-18.

17. Flammiger A, Weisbach L, Huland H, Tennstedt P, Simon R, Minner S, et al. High tissue density of FOXP3 + T cells is associated with clinical outcome in prostate cancer. Eur J Cancer 2013;49:1273-9.

18. Selby MJ, Engelhardt JJ, Quigley M, Henning KA, Chen T, Srinivasan M, et al. Anti-CTLA-4 Antibodies of IgG2a isotype enhance antitumor activity through reduction of intratumoral regulatory T cells. Cancer Immunol Res 2013;1:32-42.

19. Watson PA, Ellwood-Yen K, King JC, Wongvipat J, Lebeau MM, Sawyers CL. Context-dependent hormone-refractory progression revealed through characterization of a novel murine prostate cancer cell line. Cancer Res 2005;65: 11565-71.

20. Li B, VanRoey M, Wang C, Chen TH, Korman A, Jooss K. Antiprogrammed death-1 synergizes with granulocyte macrophage colony-stimulating factor--secreting tumor cell immunotherapy providing therapeutic benefit to mice with established tumors. Clin Cancer Res 2009;15:1623-34.

21. Selby MJ, Engelhardt JJ, Quigley M, Henning KA, Chen T, Srinivasan M, et al. Anti-CTLA-4 antibodies of IgG2a isotype enhance antitumor activity through reduction of intratumoral regulatory T cells. Cancer Immunol Res 2013; 1:32-42.

22. Nimmerjahn F, Lux A, Albert H, Woigk M, Lehmann C, Dudziak D, et al. FcgammaRIV deletion reveals its central role for IgG2a and IgG2b activity in vivo. Proc Natl Acad Sci USA 2010;107:19396-401.

23. Nimmerjahn F, Bruhns P, Horiuchi K, Ravetch JV. FcgammaRIV: a novel FcR with distinct IgG subclass specificity. Immunity 2005;23:41-51.

24. Bishop JL, Sio A, Angeles A, Roberts ME, Azad AA, Chi KN, et al. PD-L1 is highly expressed in Enzalutamide resistant prostate cancer. Oncotarget 2015;6:234-42. 